\title{
Living in clusters: the local spatial segregation of a lizard community
}

\author{
Neftalí Sillero ${ }^{1, *}$, Verónica Gomes² \\ 1 CICGE: Centro de Investigação em Ciências Geo-Espaciais, Faculdade de Ciências da Universidade do \\ Porto (FCUP), Observatório Astronómico Prof. Manuel de Barros, Alameda do Monte da Virgem, 4430-146 \\ Vila Nova de Gaia, Portugal. \\ ${ }^{2} \mathrm{CIBIO} /$ InBio, Centro de Investigação em Biodiversidade e Recursos Genéticos da Universidade do Porto, \\ Campus Agrário de Vairão, 4485-661 Vairão, Portugal. \\ *Correspondence: Phone: +351 227861290, E-mail: neftali.sillero@gmail.pt
}

Received: 1 February 2016; returned for review: 7 March 2016; accepted 30 March 2016.

Plant and animal individuals can have a random, regular, or clustered distribution across space. The analyses of these patterns are important to understand how environment influences the spatial structure of species communities. We studied the local spatial segregation in a lizard community that is composed by four species in Salamanca (Spain). We inferred if habitat and / or competition are segregating factors. We collected a total of 675 records with a high-accuracy GPS unit. We used Ripley's K function to determine the distance threshold of clustering of the whole community and of each species separately, Delaunay's triangulation (using as clustering distance threshold the Nearest Neighbor Index) to identify spatial species' clusters, and an overlapping analysis (using buffers around species records), as well as a distance comparison analysis (among intra-species and inter-species distances), to measure the species' spatial segregation. The lizard community was distributed in 34 clusters, with 13 composed by only one species and 21 composed by two or more species. Our results indicated that species of the same genus segregated almost totally, inhabiting different habitats; on the other hand, species of different genera presented partial segregation, sharing some habitats. Ground-dwelling species had partial spatial segregation as they compete for similar habitats. Saxicolous species presented a high degree of spatial segregation due to their different habitat.

Key words: GIS; Iberian Peninsula; lacertids; local distribution patterns, spatial statistics.

Viviendo en grupos: segregación espacial local en una comunidad de lacértidos. Las plantas y los animales pueden tener una distribución aleatoria, regular o agrupada. Los análisis de estos patrones son importantes para entender cómo el ambiente influye en la estructura espacial de las comunidades de especies. Se estudió una comunidad de lacértidos en Salamanca (España), compuesta por cuatro especies, con el fin de medir la segregación espacial local. Se determinó en qué medida el hábitat y / o la competencia son factores de segregación. Se recogieron un total de 675 registros con una unidad GPS de alta precisión. Se utilizó la función K de Ripley para determinar el umbral de distancia de la agrupación de toda la comunidad y de cada especie, la triangulación de Delaunay (utilizando como umbral de distancia de agrupación el índice del vecino más cercano) para identificar espacialmente los grupos de especies, y un análisis de superposición (utilizando áreas de influencia alrededor de los registros de especies), así como un análisis de comparación de la distancia (entre distancias intra-especies e inter-especies), para medir la segregación 
espacial de las especies. La comunidad se distribuyó en 34 grupos, con 13 grupos compuestos por una sola especie y 21 grupos compuestos por dos o más especies. Los resultados indican que las especies del mismo género se segregan casi totalmente, ocupando diferentes hábitats. Por otro lado, las especies de diferentes géneros presentan segregación parcial, compartiendo algunos hábitats. Además, las especies más ligadas al suelo tienen segregación espacial parcial ya que compiten por hábitats similares, mientras que las especies saxícolas presentan un alto grado de segregación espacial debido a sus diferentes hábitats.

Key words: estadística espacial, lacértidos, patrones locales de distribución, península ibérica, SIG.

The analysis of spatial patterns is an essential issue in ecology and provides insights about how organisms interact among each other or with their environment (Pianka, 1973). In particular, studying the local spatial structure of a community composed of several species is important to understand how individuals segregate spatially depending on the presence of other species (competitors, predators, preys) or other environmental resources (light, shelters, food, soil). The local spatial structure of a community can be random, regular or clustered (GoRTON et al., 1979; Frost \& Bergmann, 2012). In a random pattern, the probability of finding an individual is equal everywhere and independent of the presence of others. In a regular pattern, the probabilities of finding individuals and empty areas are the same. In a clustered pattern, the probability of finding a second individual near the first one and of finding areas without individuals are very high, but mutually exclusive: when one of these probabilities is high, the other one is low. Therefore, species can segregate locally inside a community following either random, regular or clustered patterns, depending on which resources the species share or how they compete.

Ideally, the local spatial segregation of individuals can be represented as a gradi- ent from no segregation at all to total segregation. Species will be distributed randomly if resources are abundant or widespread, regularly if resources are evenly distributed or if species are territorial, or in clusters if resources are distributed in patches. On the other hand, local spatial segregation may not exist if species do not compete even if they use similar resources. However, resource segregation is evolutionarily advantageous to minimise competition (Silvertown, 2004). Species can evolve towards the adoption of different resource use that might also lead into spatial segregation; if their niches become completely different, they will no longer compete (He et al., 1997; Martínez-Freiría et al., 2008; Grey \& HE, 2009). The intermediate situation is partial segregation, where some degree of competition among species exists due to the similarity of niches, creating syntopic zones where species might coexist at some degree ( $\mathrm{HE}$ et al., 1997; MARTínez-Freiría et al., 2008; GrAy \& He, 2009).

In order to completely understand the local spatial structure of a community of several species, it is important to analyse not only how individuals are distributed inside the community but also how species segregate locally. These analyses are performed using spatial statistics, the branch 
of statistic methods dealing with geographical entities (Rogerson, 2001; ForTin \& DALE, 2005). Spatial statistical tests help identify how the individuals are distributed, their relationship with the spatial factors (i.e. the degree of autocorrelation with the resources), and the local patterns of autocorrelation and outliers. For instance, tree species tend to be clustered, but dead individuals are randomly distributed (GETZIN et al., 2006). This pattern can change with age, from clustered distribution in younger plants to random in median-aged, and then to regular in the oldest ones, either in trees (Wells \& Getis, 1999; Gray \& He, 2009) or shrubs (Phillips \& MacMaHON, 1981; HAASE et al., 1996). The main factor driving distribution patterns in plants is competition (Phillips \& MAcMAHON, 1981; GETZIN et al., 2006), but it can be also substrate (Schenk et al., 2003). In animals, there are few studies describing how species are locally distributed. The most frequent pattern is clustered (UNDERWOOD \& Chapman, 1996), with more or less intensity (Moody et al., 1997). Some species change from regular to clustered distribution when density increases (GoRTon et al., 1979). Adults can be randomly distributed, whereas juveniles have frequently a regular distribution, as they are excluded to less suitable habitats (Frost \& Bergmann, 2012; Sillero \& GonçAlves-Seco, 2014). The tests most frequently used in the analysis of distribution patterns are related to point processes: Ripley's K function, to determine the distribution pattern along distances (Ripley, 1976); the Nearest Neighbour Index, to measure the degree of aggregation of a point process (CLARK \& Evans, 1954); Moran's I index (Moran,
1950), for global autocorrelation, i.e. the correlation of a point process related to a particular variable; and Local Indicators of Spatial Association (LISA) (Anselin, 1995), for local autocorrelation, in order to identify internal spatial patterns of autocorrelation.

The main objective of this work was to measure the local spatial segregation of a community of lizards in order to infer if habitat and / or competition are segregating factors, due to the different species' environmental requirements. The advantage of using spatial statistics is that we can infer the influence of habitat or competition as segregating factors without data on those factors, only analysing distances among individuals (PIELou, 1961). When measuring the local spatial segregation inside a species' community, habitat may be the main driving factor if the segregation is total (without sympatry areas), or there might be some degree of competition if the segregation is partial (and thus areas of sympatry occur). We studied a lizard community in Salamanca (Spain), composed by four species, two grounddwelling lizards (Podarcis carbonelli, Psammodromus algirus), one saxicolous lizard (Podarcis guadarramae guadarramae, hereafter P. guadarramae), and one active forager, largesized lizard (Timon lepidus). Our predictions were:

i) that species in the community are not distributed randomly or regularly along the study area, but in clusters, largely determined by the spatial structure of the area, as the resources are not evenly distributed.

ii) that clusters differ in their specific composition as a consequence of the 
different distribution of the species. If clusters are composed by only one species, species may have evolved to use different resources and thus segregation is total. Therefore, we forecast that grounddwelling species will present partial spatial segregation as they compete for the same habitats, whereas saxicolous species will present a high degree of spatial segregation as they live in a very different habitat. Finally, we predict that the large-sized lizard will not be influenced by the presence of the other species because of its higher trophic level.

\section{Materials and Methods}

\section{Study area}

The study area was located at the Natural Park of Batuecas-Sierra de Francia, between the villages of La Nava de Francia and El Casarito, south of Salamanca (Spain; Fig. 1). The study area included two different parts: an unpaved pathway $(1.5 \mathrm{~km})$ along an oak forest, and a rocky area, which delimits the pathway. The oak forest occupies $90 \%$ of the pathway and the remaining $10 \%$ corresponds to the rocky area border. We only surveyed the edges of the unpaved pathway because lizards use open and sunny places. As the oak forest of Quercus pyrenaica is very shaded due to the dominance of vegetation, thermoregulation places are infrequent. The pathway is part of the official tourist trips of the Natural Park of Batuecas-Sierra de Francia, and it is also used by cars, although in reduced number.

\section{Species community composition}

The lizard community was composed of one large-sized species (T. lepidus), one medium-sized species (P. algirus) and two small-sized species ( $P$. carbonelli and $P$. guadarramae), all of them belonging to the Lacertidae family. Timon lepid us (the largest lacertid species of the Iberian Peninsula) is typically a Mediterranean species (Mateo, 2015); when in Atlantic regions, it is associated with open and sunny areas. Psammodromus algirus is a ground-dwelling lizard of Mediterranean habitats, such as shrubby vegetation (SALVAdor, 2015). Podarcis guadarramae prefers rocky habitats and is found very frequently in human buildings (Diego-Rasilla \& Pérez-Mellado, 2003). Podarcis carbonelli is a grounddwelling lizard of Atlantic habitats (SÁSousa, 2008).

\section{Surveys}

We performed 19 surveys of the study area during five days (Fig. 1), at the end of May and the beginning of June 2012 (only three surveys on the first day, and four daily surveys the following four days). As lizard activity follows daily and seasonal circadian cycles (Díaz \& Cabezas-Díaz, 2004), it is difficult to detect all the species present in a community with only one sampling. The only solution is thus to perform multiple surveys, in order to guarantee that all species are detected. Repeating surveys on the same community may be considered pseudo-replication, but this is not the case here. Pseudo-replication occurs when multiple observations of the same item (in our case, the same individual) are taken on a single replicate of a treatment (here, each survey; Hurlbert, 1984; Heffner et al., 1996; Millar \& Anderson, 2004). Pseudo-replication is defined as "the failure to acknowledge the sequential measurement of multiple observations on 


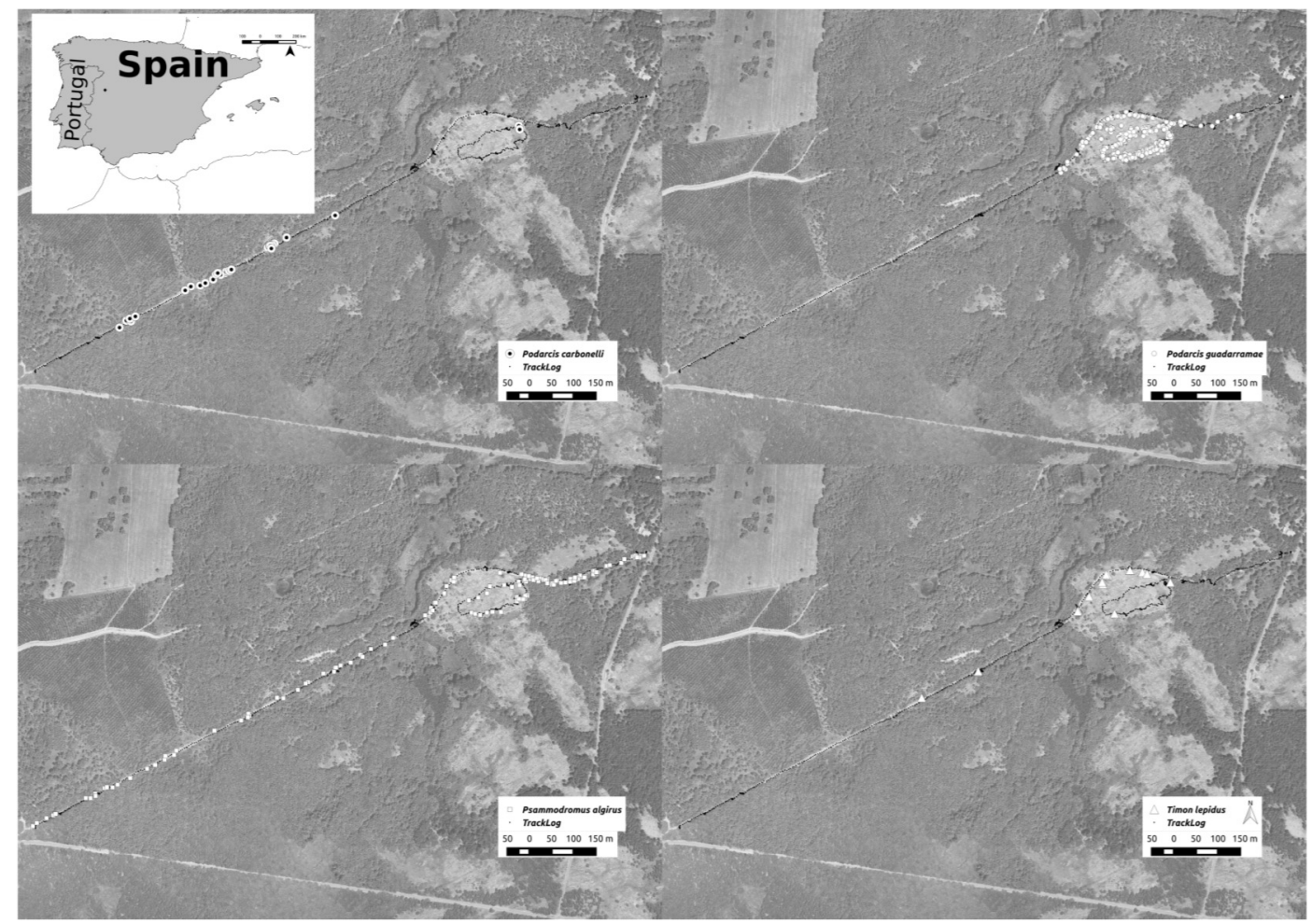

Figure 1: Location of the unpaved road between the villages of El Casarito and La Nava de Francia (southern Salamanca, Spain) and the rocky area with the point records of the four lacertid species (P. carbonelli, P. guadarramae, P. algirus and T. lepidus).

the same treatment replicate" (Millar \& Anderson, 2004). Thus, in our case, pseudo-replication should occur if multiple observations of the same individual are recorded inside each survey, but not across surveys. Each survey is independent because each recorded event conveys no information about the others, at least for our measurement capacity (see below). Probably we recorded the same individual across several surveys, but only one time per survey. We acted in a similar way to home range studies, where the same individual is recorded several times across many surveys, but not in the same survey (Powell \& Mitchell, 2012). When analysing the spatial structure of a community, it is not necessary to identify each animal individually (Gorton et al., 1979; Phillips \& MacMahon, 1981; HaAse et al., 1996; UNDerwood \& Chapman, 1996; Moody et al., 1997; Wells \& Getis, 1999; SChenk et al., 2003; Getzin et al., 2006; Gray \& He, 2009; Frost \& BERGMANN, 2012).

We performed several surveys each day: the first survey began at sunrise and the last one finished at sunset. The duration of each survey was different depending mainly on lizard activity. In spring, lizards have two periods of high activity, one in the morning and another one in the afternoon, dropping the activity considerably at noon (DíAz \& CABEzas-DíAz, 2004). Therefore, noon surveys took less time as 
lizards were less active and thus less abundant. On average, each survey took around 2 hours, starting and finishing alternatively in one extreme of the study area. We also changed the direction of the surveys every day in order to sample uniformly all the study area. We waited 15 minutes between surveys in order to guarantee that the lizards had enough time to recover their normal activity in the event that they were disturbed by our presence. In this way, we guaranteed the statistical independence of each survey. The species of each individual was visually identified without the necessity of capturing them. We recorded the position of each lizard with a GPS unit Trimble ${ }^{\circledR}$ GeoExplorer 2008 HX (Trimble, Sunnyvale, California, USA), with an accuracy around $10 \mathrm{~cm}$ after post-processing. We collected several data directly on the GPS database: species, age (adult, subadult or juvenile), and sex (male, female or undetermined).

Species have different detection probabilities, but this does not introduce a bias if the researcher knows the species' habitat preferences and thus where to look for individuals. Besides this, the four species of the studied community are easily detected if they are active, especially when thermoregulating in open spaces. Timon lepidus is a large lizard that usually thermoregulates at the top of big boulders, making it easy to detect (MATEO, 2015). Both Podarcis species, as well as P. algirus, thermoregulate frequently close to rocks and vegetation (Diego-Rasilla \& PérezMellado, 2003; SÁ-Sousa, 2008; Salvador, 2015). In our study area, P. guadarramae and T. lepidus occupy large rocky outcrops with very little vegetation, and $P$. cabornelli and $P$. algirus can be found in the unpaved pathway. Actually, P. carbonelli in the Iberian Central System is found mainly in ditches of roads and pathways crossing oak forests (SÁ-SousA, 2008).

\section{Statistical analysis}

We performed the following sequence of analysis: (1) we determined the global spatial structure of the community, (2) we located the clusters (local spatial structure) and determined the specific composition of each cluster, and (3) we quantified the spatial segregation among species with two complementary methods (overlap and distance analyses).

1) Global spatial structure of the community. We applied several tests of spatial statistics to determine if the global community distribution (the community as a whole) is random, regular, or clustered. We analysed the distance threshold of clustering for all the species together and for each species individually, using Ripley's K distance function (RIPLEY, 1976; Rogerson, 2001; Bivand et al., 2008), which measures the distribution of pairwise distances between events. Ripley's K function was calculated using the envelope function of the package "spatstat" (BADDELEY \& Turner, 2005) within the $R$ software ( $R$ Development Core Team, 2012). This function simulates repeatedly (with 999 iterations) a complete spatial randomness (CSR) point process with the same estimated intensity as the observed data, in order to test whether the empirical function is significantly different from random. An important element needed to estimate Ripley's $\mathrm{K}$ is the spatial region (so-called "window"), which has to be defined a pri- 
ori. Here, we used the Nearest Neighbor Index as the distance to define a buffer around all recorded points. This buffer constituted the window for Ripley's K function.

2) Spatial location and specific composition of clusters. We used Delaunay's triangulation to identify and locate each cluster individually. The definition of what constitutes a cluster inside a cloud of points depends on a threshold distance, i.e. the distance above which any point included in a cluster is further from any point outside the cluster. Multiple solutions are possible, depending mainly on how many points are included in the cluster and on the size of the study area. Therefore, this threshold distance should be determined statistically, for example using distance functions like the $\mathrm{K}$ function (RIPLEY, 1976). We used here the Nearest Neighbour Index (NNI) (Clark \& Evans, 1954) to determine the threshold distance because of its easier interpretation as compared to other functions. The NNI considers that points in a cloud are clustered when the mean nearest neighbour distance among points is lower than the expected value, i.e. the mean neighbour distance of a random cloud of points. NNI was obtained with the function "Nearest neighbour analysis" of QGIS 2.0. We computed the length of the lines of a Delaunay triangulation among all points, selecting those Delaunay triangles with lines shorter than the expected nearest neighbour distance (CLARK \& Evans, 1954). The points intersecting the selected Delaunay triangles were considered as clustered. These analyses were performed in QGIS 2.0 using the functions "Delaunay triangulation", "Select by attributes", and "Select by location".

3) Quantification of spatial segregation by overlap analysis. We calculated the degree of overlap between pairs of species. We calculated buffers with a radius equal to the expected nearest neighbour distance (Clark \& Evans, 1954). Overlaps were calculated with the functions "Buffer" and "Intersect" of QGIS 2.0. We expected that species with a high overlap will correspond to clusters of several species with some degree of competition and hence segregating partially. On the other hand, species without overlap will correspond to clusters of only one species using different resources than the rest and thus segregating completely. Therefore, we forecast that ground-dwelling species will present partial spatial segregation as they compete for the same habitats, while saxicolous species will present a high degree of spatial segregation as they live in a very different habitat.

4) Quantification of spatial segregation by distance analysis. In addition to the previous method, we compared distances among records within a given species with

Table 1: List of species detected and number of records per species, sex and age.

\begin{tabular}{cccccccc}
\hline Species & \multicolumn{3}{c}{ Sex } & & \multicolumn{2}{c}{ Age } & \multicolumn{2}{c}{ Total } \\
& Female & Male & Unknown & Adult & Subadult & Juvenile & \\
\hline P. carbonelli & 14 & 20 & 1 & 35 & 0 & 0 & 35 \\
P. guadarramae & 153 & 271 & 32 & 384 & 70 & 2 & 456 \\
P. algirus & 35 & 44 & 89 & 118 & 28 & 22 & 168 \\
T. lepidus & 1 & 4 & 11 & 12 & 0 & 4 & 16 \\
Total & 203 & 339 & 133 & 549 & 98 & 28 & 675 \\
\hline
\end{tabular}



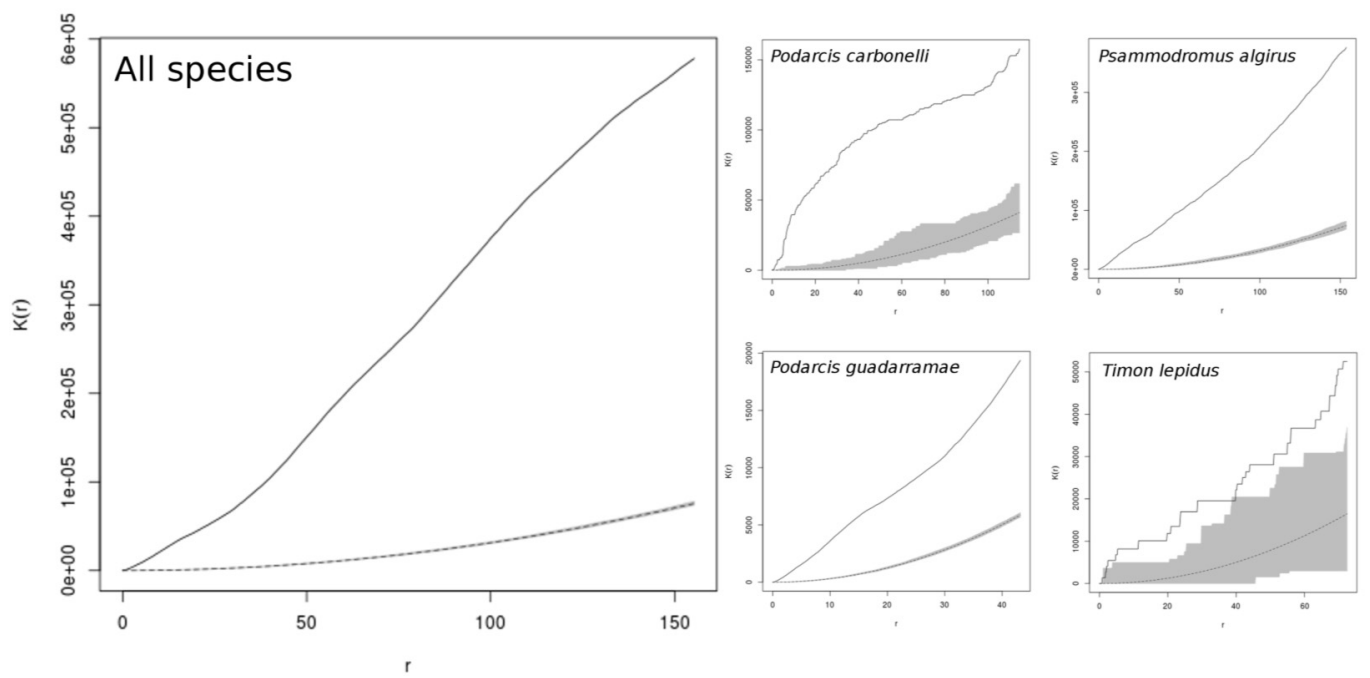

Figure 2: Ripley's K graphs of all records together and per species showing the relationship between the Ripley's K function (K(r), y axis) and the distance among points ( $r$, $x$ axis). The continuous line is the observed function of the species records, the dotted line is the theoretical function of a complete spatial randomness (CSR) point process, and the grey shadow shows the area between the lower and higher limits of the CSR point process after 999 replications. The point process is considered as clustered if the observed function is above the higher CSR limit, as regular if the function is below the lower CSR limit, and as random if it is inside the limits.

distances between that species and the other ones. We expected that distances among records within a spatially segregated species would be significantly smaller than the distances between that species and the other ones, as the records of the segregated species will be clustered and little mixed with those of other species. Therefore, we used analyses of the variance (ANOVAs) to compare the distance matrix within each species the matrix of distances with the remaining species, using $\mathrm{R}$ software ( $\mathrm{R}$ Development Core TEAM, 2012).

\section{Results}

We collected a total of 675 records, distributed as follows (Table 1): 456 P. gua- darramae, 168 P. algirus, 35 P. carbonelli, and 16 T. lepidus. Podarcis carbonelli and P. algirus occurred mainly along the pathway, while $P$. guadarramae was restricted to the rocky area. Timon lepidus occurred in the pathway and also in the border of the rocky area (Fig. 1).

\section{Global spatial patterns of the lizard com- munity}

The K-function for all the species showed that species locations had a clustered distribution: from the beginning of the graph, the curve was always above the CSR limits of the envelope analysis (Fig. 2). This clustered pattern was visible also when considering each species separately (Fig. 2). 
Spatial location and specific composition of clusters

The expected nearest neighbour distance was $17.8 \mathrm{~m}$. This distance was used to define the threshold distance of the clusters. We identified 597 species points in 34 clusters (Fig. 3 and Table 2). Nineteen clusters were situated on the pathway and 15 in the rocky area. There were 13 clusters composed by only one species, 13 by two species and seven clusters with three species (Table 2). Cluster 10 was the only cluster containing all species (Table 2 ) and also had the highest number of records (293; Fig. 3). Psammodromus algirus participated in 25 clusters, P. guadarramae in $23, T$. lepidus in 10 , and $P$. carbonelli in six.

\section{Quantification of spatial segregation among species}

Podarcis carbonelli was the most spatially segregated species (Table 3), while P. gua- darramae and $P$. algirus were the species most commonly sharing space (Table 3 ). The differences between distances among records within a given species and distances to records from the other species were highly significant (ANOVA test for logtransformed data: $\left.\mathrm{F}_{1,7}=158.8, P<0.001\right)$. The Tukey post-hoc test (Fig. 4) showed that the results were highly significant for three species (P. carbonelli, P. guadarramae, and $P$. algirus; $P<0.0001)$ but not for $T$. lepidus $(P=0.9996)$.

\section{Discussion}

As expected, the lizard community studied here, as well as each of its four species, were not distributed randomly but in clusters, probably because resources within home ranges are not distributed randomly but in patches (KWIATKOWSKI \& Sullivan, 2002). Clusters were composed by different sets of species, comprising one

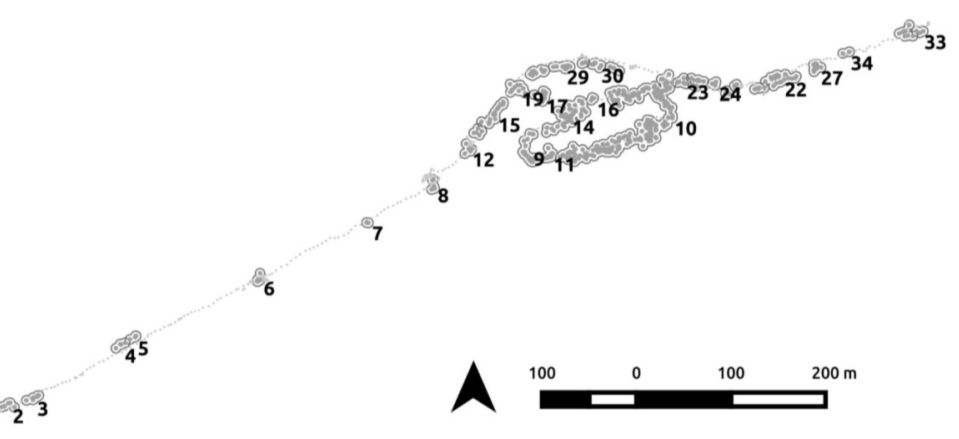

Figure 3: Distribution of clusters identified with Delaunay triangulation and the expected nearest neighbour distance (see methods for more details). Numbers refer to clusters listed in Table 2. 


\begin{tabular}{|c|c|c|c|c|c|c|c|}
\hline Cluster & P.car & P.gua & P.alg & T.lep & $\begin{array}{c}\text { Total } \\
\text { records }\end{array}$ & $\mathbf{N}$ & Table 2: Number of species \\
\hline 1 & & & 3 & & 3 & 1 & set of points whose distance to \\
\hline 2 & 4 & & 1 & & 5 & 2 & set of points whose distance to \\
\hline 3 & 7 & & & & 7 & 1 & any point inside the cluster is \\
\hline 4 & 4 & & & & 4 & 1 & further than the distance to \\
\hline 5 & 1 & & 2 & 1 & 4 & 3 & any other point outside the \\
\hline 6 & 1 & & 2 & 3 & 6 & 3 & cluster. Cluster distance was \\
\hline 7 & & & 2 & & 2 & 1 & determined using the expected \\
\hline 8 & & 5 & & & 5 & 1 & nearest neighbour distance \\
\hline 9 & & 26 & & & 26 & 1 & (see methods for more details). \\
\hline 10 & 5 & 259 & 28 & 1 & 293 & 4 & In bold the only cluster with \\
\hline 11 & & 9 & 2 & 1 & 12 & 3 & ford, the ony ciuster with \\
\hline 12 & & 1 & 3 & 2 & 6 & 3 & four species. P.car: Podarcis \\
\hline 13 & & 3 & 2 & & 5 & 2 & carbonelli, P.gua: Podarcis gua- \\
\hline 14 & & 48 & 3 & & 51 & 2 & darramae, P.alg: Psammodromus \\
\hline 15 & & 19 & 2 & 1 & 22 & 3 & algirus, T.lep: Timon lepidus, N: \\
\hline 16 & & 2 & 1 & & 3 & 2 & number of species per cluster. \\
\hline 17 & & 11 & & & 11 & 1 & \\
\hline 18 & & & 3 & & 3 & 1 & \\
\hline 19 & & 5 & 3 & 2 & 10 & 3 & \\
\hline 20 & & 3 & 2 & & 5 & 2 & \\
\hline 21 & & 1 & 2 & & 3 & 2 & \\
\hline 22 & & 1 & 21 & & 22 & 2 & \\
\hline 23 & & 1 & 5 & & 6 & 2 & \\
\hline 24 & & & 3 & & 3 & 1 & \\
\hline 25 & & 3 & 6 & & 9 & 2 & \\
\hline 26 & & 11 & & 2 & 13 & 2 & \\
\hline 27 & & 4 & 8 & & 12 & 2 & \\
\hline 28 & & 2 & 1 & 2 & 5 & 3 & \\
\hline 29 & & 11 & & & 11 & 1 & \\
\hline 30 & & 7 & & & 7 & 1 & \\
\hline 31 & & 3 & & 1 & 4 & 2 & \\
\hline 32 & & 1 & 8 & & 9 & 2 & \\
\hline 33 & & & 4 & & 4 & 1 & \\
\hline 34 & & & 3 & & 3 & 1 & \\
\hline Total & 22 & 436 & 120 & 16 & 594 & & \\
\hline
\end{tabular}

to four species, but with different frequencies. Our results showed that species of the same genus segregated almost totally, inhabiting different habitats; on the other hand, species of different genera presented partial segregation, sharing some habitats (MacArthur \& Pianka, 1966; Schoener, 1974; Pianka \& Huey, 1978; Pianka, 1980).

The pair of Podarcis species ( $P$. carbonelli and $P$. guadarramae) presented the low- est overlap, while $P$. guadarramae and $P$. algirus had the highest overlap. Also, P. carbonelli was the species with the lowest overlap across all species combinations. Podarcis carbonelli and $P$. algirus occurred not only in the pathway, but also in vegetated zones around and inside the rocky area, although $P$. algirus was not abundant there. These two species were located in the middle of the segregation gradient. Timon lep- 
Table 3: Space overlapping values by pairs of species, ranked from low to high surface area. P.car: Podarcis carbonelli, P.gua: Podarcis guadarramae, P.alg: Psammodromus algirus, T.lep: Timon lepidus.

\begin{tabular}{cc}
\hline Species pair & Area $\left(\mathbf{m}^{2}\right)$ \\
\hline P.car - P.gua & 1327.73 \\
P.car - T.lep & 2359.64 \\
P.car - P.alg & 6882.51 \\
P.alg - T.lep & 7758.69 \\
P.gua - T.lep & 8101.96 \\
P.gua - P.alg & 22638.58 \\
\hline
\end{tabular}

idus had low and high levels of overlap, because it was not influenced by the presence of other species. In fact, it appeared in the rocky area and also in the pathway although with less frequency. In addition, $P$. carbonelli was also the species with the largest difference between distances among its owns records and distances to the remaining species. Moreover, Ripley's K function graph for this species showed the less clustered pattern. The other two species ( $P$. guadarramae and $P$. algirus) presented low distance differences. Podarcis carbonelli clusters indicated a trend to segregate from the other species, as it clustered only with $P$. algirus (also a ground-dwelling species) and T. lepidus, always in low numbers. Podarcis guadarramae formed many clusters composed of numerous individuals, frequently with $P$. algirus. Again, the spatial pattern of T. lepidus indicated an independent pattern, as it clustered equally with all species.

Although both Podarcis species use preferentially some specific habitat, each of them can also be found in other habitats when its sister species is absent, a process called ecological character displacement.
For example, Podarcis bocagei, a grounddwelling species of Atlantic forests of the north-western Iberian Peninsula, can also occupy rocky areas and human walls or buildings (Kaliontzopoulou et al., 2012). Even $P$. carbonelli, a species living on margins of path-walks crossing oak forests and in beach dunes (SÁ-Sousa, 2008), also inhabits walls when $P$. guadarramae or $P$. bocagei are absent. However, there are examples of strict syntopy between grounddwelling and saxicolous Podarcis species: P. guadarramae was relegated to poor habitats by $P$. bocagei in a community in the northern limit of its distribution (SILlERo \& GoNÇalves-Seco, 2014). Actually, P. guadarramae is probably the most habitat-dependent species of all Iberian Podarcis group, as it is always associated with rocky areas (Diego-Rasilla \& Pérez-Mellado, 2003). In contrast, $P$. algirus, a species living in

Figure 4: Tukey post-hoc test results showing differences between log-transformed distances among records of each given species and records of the other species. P.car: Podarcis carbonelli, P.gua: Podarcis guadarramae, P.alg: Psammodromus algirus, T.lep: Timon lepidus.

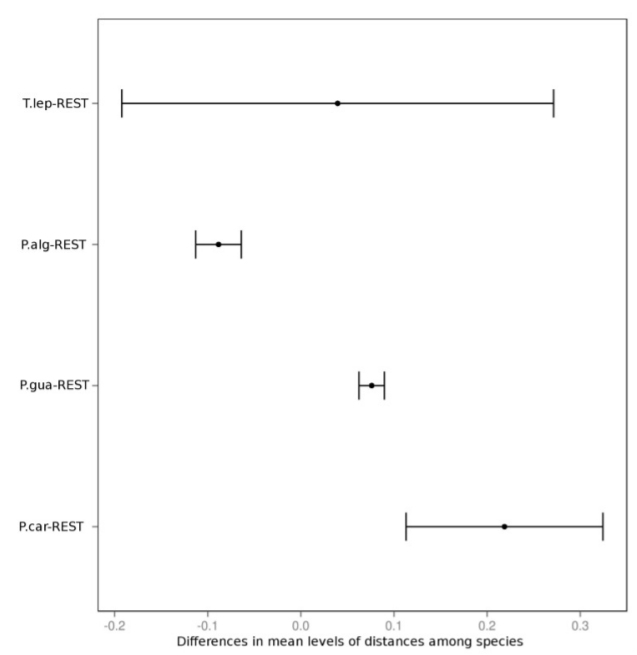


open forests and shrub-lands (SAlvador, 2015), segregated partially from P. guadarramae probably because of the presence of vegetation within the rocky area, and segregated more from P. carbonelli probably due to competition as they inhabit the same oak forests. The independent pattern showed by T. lepidus may be due to its higher trophic level and not to the use of different habitats (Матео, 2015). Thus, ground-dwelling species presented partial spatial segregation as they may compete for the same habitats, while saxicolous species presented a high degree of spatial segregation as they occupy different habitats.

This study was performed during a short period of time in spring but with a high activity of lizards. The spatial structure described for this community cannot be extrapolated to other seasons, as resources will change accordingly. Unfortunately, to our knowledge, there are not studies on how spatial structure of communities or individual species change over time. Efforts have focused on analysing differences on distribution patterns among age levels (e.g. Gray \& HE, 2009). Therefore, further research in this issue should be performed in the future.

Other studies presented similar results to ours, where local spatial segregation by habitat or competition is also associated with clustered distribution patterns (Underwood \& Chapman, 1996), with more or less intensity (Moody et al., 1997). Several studies described reptile communities where habitat is the main factor of spatial segregation (Jones \& Droge, 1980; MellaDo, 1980; SCALi \& Zuffi, 1994), and where lizard species segregated spatially due to their microhabitat (Ortega et al., 1982). Juveniles of Anolis aeneus live in open habitats instead of forests because of predation by Anolis richardi (Stamps, 1983). In the case of birds, spatial segregation can be caused by intraspecific competition (Moody et al., 1997). Bats can also segregate spatially because of habitat selection (Nicholls \& Racey, 2006). More examples are available from plants, either about segregation by competition (PhIllips \& MACMahon, 1981; HaAse et al., 1996; Getzin et al., 2006; Gray \& He, 2009) or by habitat (SCHENK et al., 2003).

Spatial statistics offers new insights to analyse the spatial structure of species communities. We can understand with a better statistical base how and why species segregate locally in space. New technologies like aerial photographs of very high resolution taken from unattended aerial vehicles (the so-called drones) will allow to analyse the influence of driving factors such as habitat and shelter distribution from a spatial point of view. In fact, what is lacking in our study is the analysis of habitat segregation as a continuous component of the environment. We hope that studies of spatial biology will be more frequent in a near future.

\section{Acknowledgement}

We thank to Elena Argaña for correcting the GPS points and to M.A. Carretero for providing the GPS unit. NS was partially supported by a post-doctoral grant (SFRH/BPD/26666/2006) and research contract (IF2013) from Fundação para a Ciência e Tecnologia (FCT, Portugal). VG was partially supported by a PhD grant (SFRH/ BD/93237/2013) from FCT. This research 
was supported by the project HOUSE (PTDC/BIA-BEC/102280/2008) from FCT, and partially by the project PTDC/BIABEC/101256/2008 from FCT.

\section{REFERENCES}

Anselin, L. (1995). Local Indicators of Spatial Association-LISA. Geographical Analysis 27: 93-115.

Baddeley, A. \& Turner, R. (2005). spatstat: An $\mathrm{R}$ package for analysing spatial point patterns. Journal of Statistical Software 12: 6.

Bivand, R.S.; Pebesma, E.J. \& Gómez-Rubio, V. (2008). Applied Spatial Data Analysis with R. Springer, New York, USA.

Clark, P.J. \& Evans, F.C. (1954). Distance to nearest neighbor as a measure of spatial relationships in populations. Ecology 35: 445-453.

Díaz, J. A. \& Cabezas-Díaz, S. (2004). Seasonal variation in the contribution of different behavioural mechanisms to lizard thermoregulation. Functional Ecology 18: 867875.

Diego-Rasilla, F.J. \& Pérez-Mellado, V. (2003). Home range and habitat selection by $\mathrm{Po}$ darcis hispanica (Squamata, Lacertidae) in Western Spain. Folia Zoologica 52: 87-98.

Fortin, M.-J. \& DALE, M. (2005): Spatial Analysis. A Guide For Ecologists. Cambridge University Press, Cambridge, UK.

Frost, C.L. \& Bergmann, P.J. (2012): Spatial distribution and habitat utilization of the zebra-tailed lizard (Callisaurus draconoides). Journal of Herpetology 46: 203-208.

Getzin, S.; Dean, C.; He, F.; Trofymow, J.A.; Wiegand, K. \& Wiegand, T. (2006). Spatial patterns and competition of tree species in a Douglas-fir chronosequence on Vancouver Island. Ecography 29: 671-682.

Gorton, R.E., Jr.; Fulmer, J. \& Bell, J.W. (1979). Spacing patterns and dominance in the cockroach, Eublaberus posticus
(Dictyoptera: Blaberidae). Journal of the Kansas Entomological Society 52: 334-343.

Gray, L. \& He, F. (2009). Spatial point-pattern analysis for detecting density-dependent competition in a boreal chronosequence of Alberta. Forest Ecology and Management 259: 98-106.

HaAse, P.; Pugnaire, F.I.; Clark, S.C. \& InColl, L.D. (1996). Spatial patterns in a two-tiered semi-arid shrubland in southeastern Spain. Journal of Vegetation Science 7: 527-534.

He, F.; Legendre, P. \& LaFrankie, J.V. (1997). Distribution patterns of tree species in a Malaysian tropical rain forest. Journal of Vegetation Science 8: 105-114.

Heffner, R.A.; Butler, M.J., IV \& Reilly, C.K. (1996). Pseudoreplication revisited. Ecology 77: 2558-2562.

Hurlbert, S.H. (1984). Pseudoreplication and the design of ecological field experiments. Ecological Monographs 54: 187-211.

Jones, S.M. \& Droge, D.L. (1980). Home range size and spatial distributions of two sympatric lizard species (Sceloporus undulatus, Holbrookia maculata) in the Sand Hills of $\mathrm{Ne}-$ braska. Herpetologica 36: 127-132.

Kaliontzopoulou, A.; Adams, D.C.; van der Meijden, A.; Perera, A. \& Carretero, M.A. (2012). Relationships between head morphology, bite performance and ecology in two species of Podarcis wall lizards. Evolutionary Ecology 26: 825-845.

Kwiatкowski, M.A. \& Sullivan, B.K. (2002). Mating system structure and population density in a polygynous lizard, Sauromalus obesus (= ater). Behavioral Ecology 13: 201-208.

MacArthur, R.H. \& Pianka, E.R. (1966). On optimal use of a patchy environment. American Naturalist 100: 603-609.

Martínez-Freiría, F.; Sillero, N.; Lizana, M. \& BRITo, J.C. (2008). GIS-based niche models identify environmental correlates sustaining a contact zone between three species of European vipers. Diversity and Distributions 14: 452-461. 
Mateo, J.A. (2015). Lagarto ocelado - Timon lepidus (Daudin,1802), In A. Salvador \& A. Marco (eds.) Enciclopedia Virtual de los Vertebrados Españoles. Museo Nacional de Ciencias Naturales, Madrid. Available at http://www.vertebradosibericos.org/. Retrieved on 19 October 2016.

Mellado, J. (1980). Utilización del espacio en una comunidad de lacértidos del matorral mediterráneo en la Reserva Biológica de Doñana. Doñana, Acta Vertebrata 7: 41-59.

Millar, R.B. \& Anderson, M.J. (2004). Remedies for pseudoreplication. Fisheries Research 70: 397-407.

Moody, A.L.; Thompson, W.A.; De Bruijn, B.; Houston, A.I. \& Goss-Custard, J.D. (1997). The analysis of the spacing of animals, with an example based on oystercatchers during the tidal cycle. Journal of Animal Ecology 66: 615-628.

Moran, P.A.P. (1950). Notes on continuous stochastic phenomena. Biometrika 37: 17-23.

Nicholls, B. \& Racey, P.A. (2006). Contrasting home-range size and spatial partitioning in cryptic and sympatric pipistrelle bats. Behavioral Ecology and Sociobiology 61: 131-142.

Ortega, A.; Maury, M.E. \& Barbault, R. (1982). Spatial organization and habitat partitioning in a mountain lizard community of Mexico. Acta Oecologica 3: 323-330.

Phillips, D.L. \& MacMahon, J.A. (1981). Competition and spacing patterns in desert shrubs. Journal of Ecology 69: 97-115.

Pianka, E.R. (1980). Guild structure in desert lizards. Oikos 35: 194-201.

PiankA, E.R. (1973). The structure of lizard communities. Annual Review of Ecology and Systematics 4: 53-74.

Pianka, E.R. \& Huey, R.B. (1978). Comparative ecology, resource utilization and niche segregation among gekkonid lizards in the Southern Kalahari. Copeia 1978: 691-701.

Pielou, E.C. (1961). Segregation and symmetry in two-species populations as studied by nearest- neighbour relationships. Journal of Ecology 49: 255-269.
Powell, R.A. \& Mitchell, M.S. (2012). What is a home range? Journal of Mammalogy 93: 948 $-958$.

R Development Core Team (2012): R: A Language and Environment for Statistical Computing. R Foundation for Statistical Computing, Vienna, Austria. Available at http://www.rproject.org/. Retrieved on 19 October 2016.

Ripley, B.D. (1976). The second-order analysis of stationary point processes. Journal of Applied Probability 13: 255-266.

Rogerson, P. (2001). Statistical Methods for Geography. SAGE Publications, London, UK.

SÁ-SousA, P. (2008). Podarcis carbonelli. Lagartixa -de-Carbonell, In A. Loureiro, N. Ferrand, M.A. Carretero, O. Paulo (eds.) Atlas dos Anfíbios e Répteis de Portugal. Instituto da Conservação da Natureza e da Biodiversidade, Lisbon, Portugal, pp. 152153.

Salvador, A. (2015). Lagartija colilarga - Psammodromus algirus (Linnaeus, 1758), In A. Salvador \& A. Marco (eds.) Enciclopedia Virtual de los Vertebrados Españoles. Museo Nacional de Ciencias Naturales, Madrid. Available at http://www.vertebradosibericos.org/. Retrieved on 19 October 2016.

Scali, S. \& Zuffi, M. (1994). Preliminary report on a reptile community ecology in a suburban habitat of northern Italy. Bollettino di Zoologia 61: 73-76.

Schenk, H.J.; Holzapfel, C.; Hamilton, J.G. \& Mahall, B.E. (2003). Spatial ecology of a small desert shrub on adjacent geological substrates. Journal of Ecology 91: 383-395.

Schoener, T.W. (1974). Resource partitioning in ecological communities. Science 185: 27-39.

Sillero, N. \& Gonçalves-Seco, L. (2014). Spatial structure analysis of a reptile community with airborne LiDAR data. International Journal of Geographical Information Science 28: 1709-1722.

Silvertown, J. (2004). Plant coexistence and the niche. Trend in Ecology and Evolution 19: 605-611.

Stamps, J.A. (1983). Territoriality and the de- 
fence of predator-refuges in juvenile lizards. Animal Behaviour 31: 857-870.

Underwood, A.J. \& Chapman, M.G. (1996). Scales of spatial patterns of distribution of intertidal invertebrates. Oecologia 107: 212-
224.

Wells, M.L. \& Getis, A. (1999). The spatial characteristics of stand structure in Pinus torreyana. Plant Ecology 143: 153-170. 